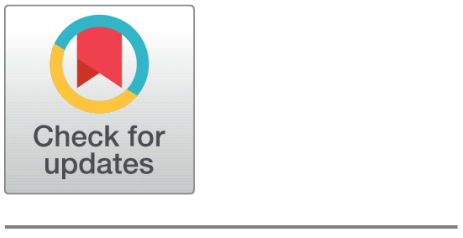

OPEN ACCESS

Received: 06.04.2021

Accepted: 09.06.2021

Published: 06.07.2021

Citation: Sudha IP, Singh J, Sodhi GS (2021) Digital Dermatoglyphics as predictive biomarkers of genetic Criminal Tendency. Indian Journal of Science and Technology 14(23): 1944-1952. https://doi.org/ 10.17485/IJST/v14i23.578

* Corresponding author.

indirasudha@gmail.com

Funding: None

Competing Interests: None

Copyright: (c) 2021 Sudha et al. This is an open access article distributed under the terms of the Creative Commons Attribution License, which permits unrestricted use, distribution, and reproduction in any medium, provided the original author and source are credited.

Published By Indian Society for Education and Environment (iSee)

ISSN

Print: 0974-6846

Electronic: 0974-5645

\section{Digital Dermatoglyphics as predictive biomarkers of genetic Criminal Tendency}

\author{
Indira P Sudha ${ }^{1 *}$, Jyoti Singh ${ }^{2}$, G S Sodhi ${ }^{3}$ \\ 1 Research scholar, Amity Institute of Forensic Sciences, Amity University, Noida, India \\ 2 Assistant Professor, Amity Institute of Forensic Sciences, Amity University, Noida, India \\ 3 Associate Professor, Ph.D, Forensic Science Unit, S.G.T.B. Khalsa College, University of \\ Delhi, Delhi, India
}

\section{Abstract}

Objectives: To ascertain the association between digital dermatoglyphics and criminal tendency and to analyze which dermatographic pattern is found more among the criminal group. Methods: The study was conducted on 90 subjects of each group. Fingerprints of the Right Hand and Left Hand of the control group and the criminal group in the age range of 18-70 were collected using the Cummins inking method. Each Fingerprint of both the groups was compared for frequency of occurrence of Arch pattern, loop, and whorls. Arithmetical mean, percentage, chi-square was done to compute the results. Findings: Whorl patterns were found more prominently and loop patterns were less in the hands of the criminals than in the control group. The little and ring fingers showed less or nil frequency of occurrence of arches in both groups. This is supported by the study of the researchers, where it was noticed that lower frequencies of arches were found in digits IV and V and highest on digit II than on digit I occurred. Chi-square was found to be statistically significant @0.05 level of significance. The present study would help largely in controlling crime as dermatoglyphics are non-invasive, economic, and convenient to handle. Using dermatoglyphics as a predictive tool would help in providing a suitable environment for the normal growth of an individual who is 'at risk' due to biological interaction. Novelty: It's a novel method to detect criminality at an early stage. Individuals at risk of becoming criminals can be checked and discouraged by providing a suitable environment.

Keywords: Criminal tendency; Digital Dermatoglyphics; Biological interaction; Preliminary Diagnosis; Predictive tool; Genetics

\section{Introduction}

Crime is an illegal act and not approved of by society, committed by someone for which he is liable for punishment by the Government. Criminologists visualize the criminal behaviour of a person as an outcome of a combination of genetic traits and social circumstances. Genes point towards criminal tendency but do not lead but it is the 
circumstances that force and they both combinedly create a large fraction of criminals. Exposure to violence everywhere around them desensitizes youth and adolescents. Preventive measures such as the use of scientific tools, community involvement, awareness drives, signing anti-bullying affidavits in schools to curb crime after the onset of criminal attitude are normal but predictive measures are essential to curb the crime and protect the children who are in the zone of risk. One such predictive measure is the study of digital dermatoglyphics. The method is non-invasive and economical at schools. It can be implemented with ease and regular monitoring of the 'at risk' children and providing suitable home-school balance can restrict the growth of criminal tendency.

\subsection{Introduction to Dermatoglyphics:}

Dermatoglyphics, a Greek word, is a combination of two words [Derma= Skin, and Glyphic=creases] and it means scientifically studying elevations and depressions on fingers and palms. The ridges are formed in the early stages of the development of an embryo when it has direction genetically to form organs. Our skin is composed of three layers: Epidermis, dermis, and hypodermis. The main purpose of epidermal friction ridges is to provide traction between the object and the skin surface. Nowadays, they are used to establish identity especially in identifying a suspect through the comparison of fingerprints found at the crime scene, thereby aiding the investigation itself. There are two important principles of dermatoglyphics and they are uniqueness and permanency of their characteristics and they remain unchanged throughout life.

\subsection{Digital Dermatoglyphics:}

A Fingerprint is defined as a representation of the bulb of the first phalange portion of a digit. It is composed of ridges and furrows arranged in the form of a pattern. Each ridge, in turn, is punctuated by a line of sweat pores which have its base in the dermis in the form of a sweat gland. The area between the ridges does not carry sweat pores. A fingerprint has two fixed points: Core and Delta ${ }^{(1)}$.

1. Core: It is an essential and the innermost part of a pattern. It is also called the inner terminus. The appearance of a core could be like a small circle, a dot or a rod, etc. Different patterns exhibit different types of cores.

2. Delta: It is another essential part of a pattern and it is also called the outer terminus. It looks like a triangle. If two ridges running side by side deviate and enclose the pattern in their center, it is said to be a divergent delta. If a single ridge bifurcates and then engulfs the pattern, it is termed as a bifurcation delta.

3. Fingerprint patterns: Topmost area of the finger exhibits various designs which are called patterns. There are three important ridge patterns: a] Arches [A], b] Loops [U], c] Whorls [W]. They are as explained below:

- Arches: The ridges run from one end of the digit to the other end like a wave. They have no delta formation. If it exhibits a tent formation in the center, it is called a tented arch. Figure $1[a, b]$ as shown exhibits arch \& tented arch. They are represented as A.

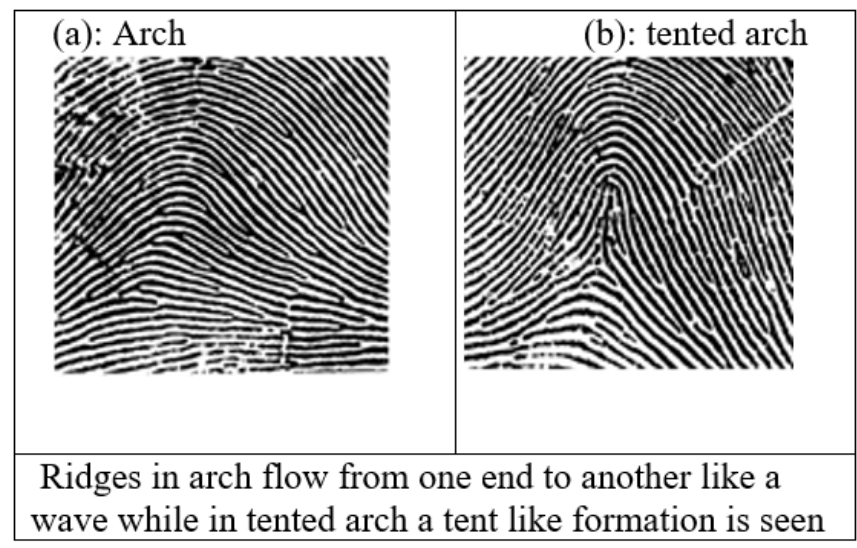

Fig 1. Arch 
- Loops: In this pattern ridges recurve but they don't turn fully and exit from the same side of the entrance. They have a core and a delta. The ridges could enter from the direction of the thumb or little side [ulnar or radial bone]. Accordingly, they are called the Radial loop or Ulnar loop. Figure 2 as shown exhibits Loops.(L)

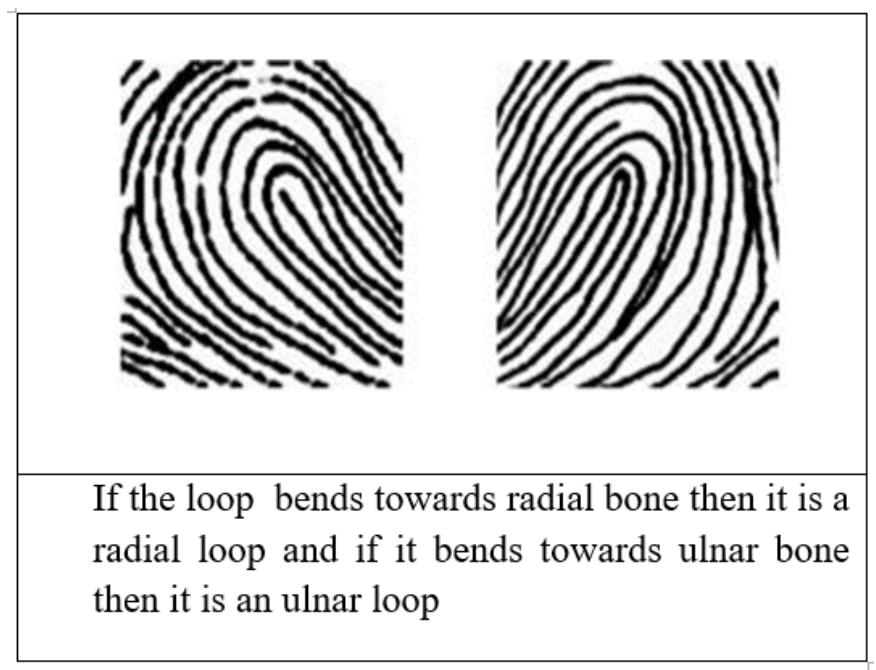

Fig 2. Loops

- Whorl: The ridges are either concentric or spiral. The pattern contains two or more deltas and core. Double-loop whorls are the only patterns having two cores. There are different types of whorls: i] concentric whorls, ii] spiral whorls, iii] central pocket whorls iv] Double-loop whorls v] Accidental whorls. Figure 3 as shown exhibits various whorls (W).

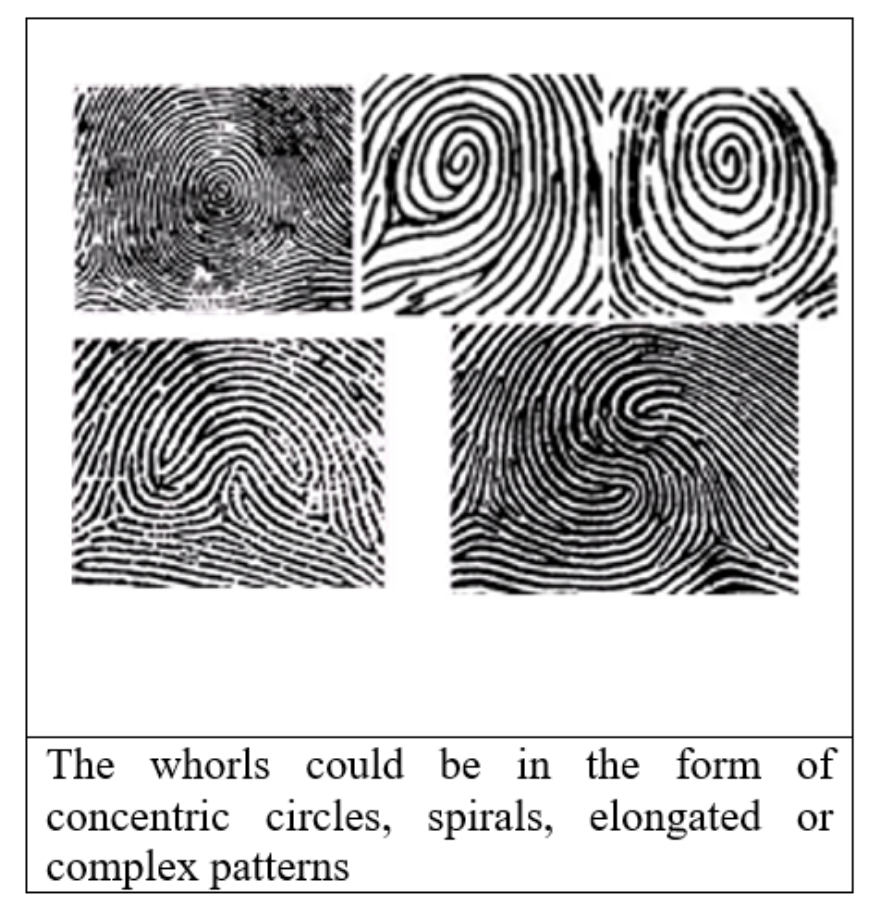

Fig 3. Types of Whorls 


\subsection{Dermatoglyphics and Genetics:}

Dermatoglyphic patterns and brain cells are said to be formed at the same time and their development phase is controlled by the neocortex part of the brain. A lot of work has been done using digital dermatoglyphics in research, understanding the potential of an individual/ inherent talent/vocation ${ }^{(2)}$ and study of the character of a person ${ }^{(3)}$. Apart from the forensic use of dermatoglyphics, Dermatoglyphics was also found useful in clinical medicine ${ }^{(4)}$ and many researchers are utilizing the association between dermatoglyphics and genetics to study various diseases as Cancer ${ }^{(5,6)}$, diabetes ${ }^{(7)}$, Leprosy ${ }^{\left({ }^{(8)}\right.}$, schizophrenia $^{(9)}$ \& mental retardation ${ }^{(10)}$.

In the study of human Genetics and criminal behaviour ${ }^{(11)}$, it was found that the tendency to commit crimes is genetically controlled. Researchers utilized fingertip features as fingerprint ridge density, ridge counts, palm print ridge density, palmar dermatoglyphics, etc to identify criminals ${ }^{(12)}$. Sudha et al., ${ }^{(13)}$ reported that offenders of law possessed more whorl patterns than control group. ‘

Pricilla et al., ${ }^{(14)}$ found differences in dermatoglyphic traits between female convicted criminals and controls. Yarovenko ${ }^{(15)}$ studied dermatoglyphics of a person who killed 19 people and found whorl patterns in both right and left digits.

Karim et al., ${ }^{(16)}$ in their demographic studies of the violent criminals in Erbil city found a lower frequency of whorls than the control groups, suggesting a strong association between crime and dermatoglyphics.

\subsection{Aims \& objectives of the present study:}

Few researchers worked to study crime but not the criminal tendency, which is a genetic factor. The present study aims to ascertain the association between criminal tendency and dermatoglyphics.

\section{Objectives of the study:}

To analyze and compare :

1. Fingerprints on both hands $[\mathrm{LH} \& \mathrm{RH}]$ of criminals

2. Fingerprints on both hands $[\mathrm{LH} \& \mathrm{RH}]$ of the control group

3. Establish the role of genetically modified dermatoglyphics with criminal tendency.

4. To analyse which dermatographic pattern is found more among the criminal group.

\subsection{Abbreviations:}

RT [Right thumb], RI [right index], RM [right middle], RR [right ring], RL [right little], LT [left thumb], LI [left index], LM [left middle], LR [left ring], LL [left little], RH [right hand] and LH [left hand].

\section{Materials and Methods}

\subsection{Research design:}

The research design selected was for a case-control study. The research design employed is a quantitative type study, designed to establish a relationship between two genetically connected variables: dermatoglyphics and criminal attitude.

\subsection{Participants}

The study participants were criminals and control groups in the age group of 18-70. The study of the whole population is not practical, so a set of participants from both groups was considered. This set was called a sample. As samples of both hands were needed for the study, a sample size of $</=100$ was considered. The control group was made of volunteers, who were informed of the objectives and written permission was sought. For Criminals handprints, Central Finger Print Bureau, MHA was approached. It is the repository of handprints of criminals. Clear and complete handprints were obtained.

\subsection{Data acquisition:}

For the study, clear ten-digit fingerprint samples of rolled as well as plain prints were acquired of both hands. Fingerprints of 90 subjects were obtained from the control group. Fingerprints of 90 criminals were obtained for the criminal group. Materials used were black printer ink [Sirchie], Finger /palm print taking bench, roller, Fingerprint forms with blocks for each finger, cleansers, pens, and a LED magnifier. 
a] Exclusion:

- Fingerprints that were not clear or partial were not considered.

- Fingerprints of people with skin allergies were not taken.

b] Inclusion:

- Age criteria taken were 18 yrs to $70 y r s$.

- Both sexes were included together. No separate data was maintained.

- Both hands were inked and printed.

\subsection{Sampling procedure:}

The prints were taken according to the manual ink method.

- Subjects washed their hands well with soap and water to remove any dirt on their fingers

- Fingers were air-dried well before taking fingerprints.

- A little amount of Ink was put on the steel plate and spread evenly, to avoid lumps.

- The subjects inked their Right-hand fingers, one by one, by rolling them on the plate.

- The inked fingers were placed then on the paper and rotated to obtain rolled fingers.

- Next, subjects placed fingers together, at the bottom of the sheet for giving a sample of RH plain fingers.

- The same process was repeated with left-hand fingers to obtain rolled and plain prints.

- Both the thumbs were taken separately

- The impressions so obtained were checked to ensure completeness of details through a magnifier.

- If the prints are not clear, a new set of prints were taken.

- After the impressions were obtained, names were noted on the slip.

- A similar method was advised to obtain fingerprints of criminals.

- The authors' supervised the total inking procedure, the examination of the inked forms, and overall entry of data into datasheets.

\subsection{Data Entry:}

A separate spreadsheet was created each for the criminal and control group and their details were entered. Each subject was assigned a group label along with a separate serial number in an alphanumeric manner. The name, serial number, and their digital dermatoglyphics were entered for analysis in the excel spreadsheets.

\subsection{Statistical analysis:}

Continuous data was shown as Standard deviation and categorical data was represented as percentages in the tables. For calculations; mean, maximum, percentage, adding were done on excel worksheets. All statistical calculations as Chi-square were done on the appropriate software. A value of $\mathrm{p}<0.05$ was considered significant.

\section{Result and Discussion}

The data so obtained was analyzed and the three major groups "A, U, W" [arch, loop, whorl] were observed in the data. Similar patterns as arches and tented arches were counted together. Similarly, radial loops and ulnar loops were combined and Whorls and other types of valued patterns were taken together. The results obtained were tabulated for easy reference in various tables given below [Tables 1, 2 and 3]. 
Table 1. Distribution of Fingerprint patterns among the controls

Distribution of Fingerprint patterns among the controls in the Right Hand. (N=90)

\begin{tabular}{|c|c|c|c|c|c|c|c|}
\hline Sl. No & Pattern & RT & RI & RM & $\mathrm{RR}$ & $\mathrm{RL}$ & Total \\
\hline 1 & Arch & $2(2.22 \%)$ & $8(8.9 \%)$ & $2(2.22 \%)$ & $0(0 \%)$ & $1(1.11 \%)$ & $13(2.89 \%)$ \\
\hline 2 & Loop & $52(57.8 \%)$ & $53(58.9 \%)$ & $71(78.9 \%$ & $47(52.2 \%)$ & $70(77.8 \%)$ & $293(65.13 \%)$ \\
\hline 3 & Whorl & $36(40 \%)$ & $29(32.2 \%)$ & $17(18.8 \%)$ & $43(47.8 \%)$ & $19(21.1 \%)$ & $144(31.98 \%)$ \\
\hline \multicolumn{8}{|c|}{ Distribution of Fingerprint patterns among the controls in the Left Hand. $(\mathrm{N}=90)$} \\
\hline Sno & Pattern & LT & LI & LM & LR & LL & Total \\
\hline 1 & Arch & $3(3.33 \%)$ & $13(14.4 \%)$ & $4(4.44 \%)$ & $0(0 \%)$ & $1(1.11 \%)$ & $21(4.66 \%)$ \\
\hline 2 & Loop & $57(63.3 \%)$ & $51(56.6 \%)$ & $66(73.3 \%)$ & $49(54.4 \%)$ & $69(76.6 \%)$ & $292(64.89 \%)$ \\
\hline 3 & Whorl & $30(33.3 \%)$ & $26(28.8 \%)$ & $20(22.2 \%)$ & $41(45.5 \%)$ & $20(22.2 \%)$ & $137(30.46 \%)$ \\
\hline
\end{tabular}

Table 2. Distribution of Fingerprint patterns among the criminals

\begin{tabular}{|c|c|c|c|c|c|c|c|}
\hline \multicolumn{8}{|c|}{ Distribution of Fingerprint patterns among the criminals in the Right Hand. $(\mathrm{N}=90)$} \\
\hline Sno & Pattern & RT & RI & RM & RR & $\mathrm{RL}$ & Total \\
\hline 1 & Arch & $1(1.11 \%)$ & $10(11.1 \%)$ & $1(1.11 \%)$ & $0(0 \%)$ & $0(0 \%)$ & $12(2.66 \%)$ \\
\hline 2 & Loop & $33(36.6 \%)$ & $36(40 \%)$ & $64(71.1 \%)$ & $30(33.3 \%)$ & $74(82.2 \%)$ & $237(52.72 \%)$ \\
\hline 3 & Whorl & $56(62.2 \%)$ & $44(48.8 \%)$ & $25(27.7 \%)$ & $60(66.6 \%)$ & $16(17.7 \%)$ & $201(44.62 \%)$ \\
\hline \multicolumn{8}{|c|}{ Distribution of Fingerprint patterns among the criminals in the Left Hand.(N=90) } \\
\hline Sno & Pattern & LT & LI & LM & LR & LL & Total \\
\hline 1 & Arch & $5(5.55 \%)$ & $11(12.2 \%)$ & $3(3.33 \%)$ & $0(0 \%)$ & $2(2.22 \%)$ & $21(4.66 \%)$ \\
\hline 2 & Loop & $38(42.2 \%)$ & $41(45.5 \%)$ & $65(72.2 \%)$ & $49(54.4 \%)$ & $74(82.2 \%)$ & $267(59.38 \%)$ \\
\hline 3 & Whorl & $47(52.2 \%)$ & $38(42.2 \%)$ & $22(24.4 \%)$ & $41(45.5 \%)$ & $14(15.5 \%)$ & $162(35.96 \%)$ \\
\hline
\end{tabular}

Table 3. Total distribution of Fingerprint patterns among the criminals and control (RH \& LH)

\begin{tabular}{lllllll}
\hline Pattern & Criminal group & & N=90 & Control group & \multicolumn{2}{c}{ N=90 } \\
\hline A & RH & LH & Total & RH & LH & Total \\
U & $2.66 \%$ & $4.66 \%$ & $3.66 \%$ & $2.89 \%$ & $4.66 \%$ & $3.77 \%$ \\
W & $52.72 \%$ & $59.38 \%$ & $56.05 \%$ & $65.13 \%$ & $64.89 \%$ & $65.01 \%$ \\
\hline
\end{tabular}

$\chi 2=1.8 .<\mathrm{CV}=5.99 @ 0.05$ level of significance

1. Distribution of Fingerprint patterns among the controls in the Right -Hand \& Left- Hand

2. Distribution of Fingerprint patterns among the criminals in the Right- Hand \& Left -Hand

3. Total distribution of Fingerprint patterns among the criminals and control [RH \& LH].

\subsection{Discussion}

After a comparison of both hands in both groups, the following observations were made:

\section{A) ARCH PATTERN:}

- Table 1 illustrates that in the case of the control group, the arch pattern was found to be the highest in the Right Index \& the Left Index at $8.9 \%$ \& $14.4 \%$ respectively. Arches frequency was highest in the left Index at $14.4 \%$, followed by Left Middle at $4.44 \%$, next in Left Thumb at 3.33\%, and least in left little at $1.11 \%$. And in the case of the right hand, the Middle and Thumb digits exhibited frequency at $2.22 \%$ and the least value was found in right little at $1.11 \%$. Arch patterns didn't occur on the Left Ring \& Right Ring fingers in the control group.

- Table 2 illustrates that in the case of the criminal group, the arch pattern in the right Index peaked at $11.1 \%$ followed by a sharp fall in values of the arch on the right thumb and right middle [1.11\%]. In comparison, the index finger of the 
left hand showed the frequency of occurrence of arches at $12.2 \%$, followed by the left thumb [5.55\%] and the left middle [3.33\%], and lastly the little finger [2.22\%]. The Left ring finger did not display an arch pattern and it was found that the right ring finger, as well as the right little, also did not show an arch pattern. The little and ring fingers showed less or nil frequency of occurrence of arches in both groups.

This is supported by the study of Maninder Kaur et al., ${ }^{(17)}$ where it was noticed that lower frequencies of arches were found in digits IV and V and higher on digit I II than on digit I occurred.

\section{B) LOOP PATTERN:}

- Table 1 illustrates that, when the loop pattern was considered in both hands of the control group, the Right middle showed loop at the highest value at $78.9 \%$ followed by right little [77.8\%], next Right Index [58.9\%], Right Thumb [57.8\%] and lastly the Right Ring [52.2\%]. In comparison, the little finger in the left hand had its highest peak at $76.6 \%$ and was followed by left middle [73.3\%], left Thumb [63.3\%], then left index [56.6\%], and least in the left ring [54.4\%].

- Table 2 illustrates that when the loop patterns in both hands of criminals were compared, little fingers of both hands exhibited the highest frequency [82.2\%] followed by middle fingers at $72.2 \%$ \& $71.1 \%$ in left and right hands. In the left hand, the left ring followed at a frequency [54.4\%], the next digit being the left index [45.5\%], and the least value was found in the left thumb [42.2\%] whereas, in comparison, the right index followed [40\%], next right thumb [36.6\%] and right ring [33.3\%]. Each finger displayed a significant difference from its control counterpart.

The present study showed that loops in the left hand exhibited the highest frequency range than the left hand in criminals. Such trends of the loop in the left hand are in agreement with the study of Pandey \& Vyas ${ }^{(18)}$.

\section{C) WHORL PATTERN:}

- Table 1 illustrates that the whorls in comparison showed higher frequency in the ring finger. The right ring had a higher frequency at $47.8 \%$ whereas the left ring had a frequency of $45.5 \%$ in the control group. They were followed by the right thumb [40\%] and left thumb [33.3\%] respectively. This is in agreement with the studies done by Maninder Kaur et al., ${ }^{(17)}$. Then, in the right hand, RT was followed by the index finger [32.2\%], little finger [21.1\%], and lastly by middle finger [18.8\%]. In the case of the left hand, the left thumb was followed by the index finger at a frequency of $28.8 \%$ which in turn was followed by the middle and little fingers [22.2\%].

- Table 2 illustrates, in comparison, that the right ring was prominent in criminals [66.6\%] followed by right thumb [62.2\%], next right index [48.8\%], the right middle [27.2\%], and significantly low value of right little [17.7\%]. Whereas in the left hand, the thumb was found at the highest frequency [52.2\%] followed by the ring [45.5\%], the next index [42.2\%], the middle [24.4\%] with low values at the little finger [15.5\%].

It had been observed that whorls were found at a higher frequency in the ring finger in the right hand of the criminals' group [66.6\%] than the control group [47.8\%] whereas in comparison, in the left hand, the whorl frequency decreased in value as well as shifted in the position of the digit as well. Frequency in Left thumb for whorls was at $52.2 \%$ in criminals when compared to the control group ring finger at $45.5 \%$.

The present study showed that in both groups, whorls were at a higher frequency range in right-hand fingers than their lefthand finger. This is in agreement with the observations of Pandey \&Vyas ${ }^{(18)}$ that whorl patterns are found at a higher frequency in right-hand fingers than left-hand fingers.

- Table 3 gives the overall values of the patterns in both groups. Accordingly, the loops were less in the criminals [56.5\%] and more in the controls [65.01\%]. The study was contrary to the study of Agarwal [19] who found that the loops were more common in criminals than in the control group. Whorls were found more in criminals [40.29\%] and less in controls [31.22\%]. The present study is in agreement with the results of Karim et al., ${ }^{(16)}$.

Arches were slightly higher in the control [3.77\%] than in the criminals' group [3.66\%]. It is contradictory to the study of Pandey $\&$ Vyas who found more arches in the criminal group. Similar is the case study done by Pricilla ${ }^{(14)}$, wherein higher frequencies of arch patterns were observed in the female convicted criminals compared with controls.

Generally, the occurrence of loops [60-65\%] worldwide is more followed by whorls [30-35\%] and arches [5-7\%] [1\&21], though some researchers reported variation in the occurrence of loops and other patterns from population to population. In Table 3, values of all the patterns are given for both hands. Arches fell below the expected value in both groups. In criminals, loops [56.5\%] were less than the general trend and similarly, whorls [40.29\%] were more than the expected value, whereas, in 
the control group, whorls and loops both were in the range of expected value. The variance in values in criminals indicated some abnormality caused due to genetic interference. Chi-square values were found to be statistically significant $[\mathrm{X} 2<\mathrm{CV}]$ @0.05 level of significance.

\section{Conclusion}

The current study demonstrated and ascertained the association between dermatoglyphics and criminal tendencies. There was a significant difference between the distribution of various fingerprint patterns on each digit of RH \& LH of Criminal and control groups. By utilizing the study of digital dermatoglyphics in the early years of schools, predicting policing can be established in high crime areas. This would benefit society by keeping a hold on criminal activities and future recidivism. By attending to the requirements of 'at risk' children and understanding the criminal mind, the happening of criminal activity can be reduced. By observing their peer group, others also would deter from committing crimes.

The authors acknowledge that further studies involving progressive data are required to clear away any doubts and to reach a clear decision. Studies involving the whole of the palm and its other parameters as ATD angle, flexion creases, etc should also be part of the study to shed more information. The dermatoglyphic investigation is economic, convenient, easy to handle, and requires neither hospitalization nor a big laboratory setup. Findings from such studies could be used to form a database to develop preventive and interceptive methods. Dermatoglyphics can act as a predictor tool to identify potential criminals and deter the growth of criminal tendencies from an early age. It is also true that news of genetic nature of criminality would pose enormous challenges and would bring issues of freewill, moral and legal conceptions. This research paper aims to find the aspects of behavioural genetics leading to criminal tendency and violence.

\section{Acknowledgements}

The authors are grateful to all the participants for their Co-operation in giving finger prints. In addition, authors are grateful to CFPB, National Crime Records Bureau, India for providing support in making available finger and palm prints slips of criminals.

\section{References}

1) Sudha SI. Biometrics and Fingerprint analysis. Selective \& Scientific Books publication. 2013. Available from: http://www.ssbook.in/index.html.

2) Gupta K. DMIT as a Career Guide: Case Study on Brainbow-A DMIT Solution Provider. SSRN. 2018;p. 1-21. Available from: https://papers.ssrn.com/ sol3/papers.cfm?abstract_id=3203826.

3) Campbell E. Fingerprints and Behaviour: A Textbook on Fingerprints and Behavioural Correspondences;vol. 1. 2012. Available from: https://www. bookdepository.com/Fingerprints-Behavior-Edward-D-Campbell/9780983479512?ref=grid-view\&qid=1617727239904\&sr=1-1.

4) Kaur J, Batra AP. Role of dermatoglyphics in medical disorders. Indian Journal of Fundamental and Applied Life Sciences. 2013;3(3):536.

5) Smail HO. Dermatoglyphics in common: genetic disorders and cancers. Micro Medicine. 2020;23(8):55-62. Available from: 10.5281/zenodo.3996477.

6) Abbasi S, Einollahi N, Dashti N, Vaez-Zadeh F. Study of dermatoglyphic patterns of hands in women with breast cancer. Pakistan Journal of Medical Sciences. 2006;22(1):18. Available from: http://pjms.com.pk/issues/janmar06/article/article3.html.

7) Desai SD, Hadimani GA. Dermatoglyphics and Health. Anatomica Karnataka. 2013;7(1):1-9. Available from: https://www.researchgate.net/publication/ 236731163_Dermatoglyphics_and_Health.

8) Natekar PE, DeSouza FM. Digital dermatoglyphics in leprosy. The Anthropologist. 2007;9(1):63-66. Available from: 10.1080/09720073.2007.11890981.

9) Bramon E, Walshe M, McDonald C, Martín B, Toulopoulou T, Wickham H, et al. Dermatoglyphics and schizophrenia: a meta-analysis and investigation of the impact of obstetric complications upon a-b ridge count. Schizophrenia Research. 2005;75(2-3):399-404. Available from: https://doi.org/10.1016/j. schres.2004.08.022.

10) Dar H, Jaffe M. Dermatoglyphic and Palmar-crease Alterations as Indicators of Early Intra-uterine Insult in Mental Retardation. Developmental Medicine $\&$ Child Neurology. 2008;25(1):53-59. Available from: https://doi.org/10.1111/j.1469-8749.1983.tb13721.x.

11) Lagoa A, Santos A, Pinheiro MF, Magalhães T. Genetics and criminal behaviour: recent accomplishments. Medicine, Science and the Law. 2009;49(4):274282. Available from: https://doi.org/10.1258/rsmmsl.49.4.274.

12) Kapoor N, Badiye A. Sex differences in the thumbprint ridge density in a central Indian population. Egyptian Journal of Forensic Sciences. 2015;5(1):23-29. Available from: https://dx.doi.org/10.1016/j.ejfs.2014.05.001.

13) Sudha IP, Singh J, Sodhi GS. Dermatoglyphics of Criminals and Effects of Social Environment: A Study. The Indian Police Journal. 2020. Available from: https://bprd.nic.in/WriteReadData/userfiles/file/202104200330035982091ipj1.pdf\#page=134.

14) Pricilla ONC, Samuel EC, Sunday IP, Kenneth OC. Dermatoglyphic patterns of female convicted criminals in Anambra state. Forensic Research \& Criminology International Journal. 2018;6(4):294. Available from: https://medcraveonline.com/FRCIJ/FRCIJ-06-00219.php.

15) Yarovenko V. Study of the Relationship of Papillary Pattern Criminal Conduct of Human. Asian Social Science. 2015;11(16):349. Available from: https://dx.doi.org/10.5539/ass.v11n16p349.

16) Karim KJ, Mustafa SK, Saleem MA, Omar RA. Dermatoglyphics Study of a Group of Violent Criminals \& Sexual Offenders in Erbil City. J Adv Lab Res Biol. 2019;10(4). Available from: http://www.ipindexing.com/journal-article-file/21843/ Dermatoglyphicsstudyofagroupofviolentcriminalssexualoffendersinerbilcity.

17) Kaur M, Kaur M, Kamal P, Kaur J. Sex Distinction in Digital Dermatoglyphic Patterns of Convicted Prisoners: A Comparative Cohort-Control Study. Arab Journal of Forensic Sciences \& Forensic Medicine. 2019;1(10):1403-1411. Available from: 10.26735/16586794.2019.030. 
18) Pandey A, Vyas JM. A Comparative Case Study of Fingerprint Patterns in Male Convicts of Sabarmati Jail (Ahmedabad) in Gujarati Population. Indian Journal of Forensic Medicine \& Toxicology. 2014;8(1):1-1. Available from: https://dx.doi.org/10.5958/j.0973-9130.8.1.001. 